\title{
Experiences of lower limb prosthetic users in a rural setting in the Mpumalanga Province, South Africa
}

\author{
Liezel Ennion and Sarah Manig
}

\begin{abstract}
Background: Ambulation with a prosthesis is the ultimate goal of rehabilitation for a person with a major lower limb amputation. Due to challenges with prosthetic service delivery in rural settings, many patients with amputations are not benefitting from prosthetic interventions. Inaccessibility to prosthetic services results in worse functional outcomes and quality of life. Learning from the experiences of current prosthetic users in this setting can assist to improve prosthetic service delivery.

Objectives: To explore the experiences of lower limb prosthetic users and to understand the importance of a lower limb prosthesis to a prosthetic user in a rural area of South Africa.

Study design: A generic qualitative approach and an explorative design were utilised in this study.

Methods: A semi-structured interview guide was used to collect data from nine prosthetic users in a rural area in the Mpumalanga province of South Africa. Interviews were audiorecorded, transcribed verbatim and analysed thematically. Demographic details and information related to acute in-patient rehabilitation were analysed descriptively.

Results: All participants were independent in activities of daily living with their prosthesis and participated actively in their community. Participants reported that their prosthesis was essential to their functioning. High travel cost was highlighted as a barrier to the maintenance of their prosthesis. Patients were dissatisfied with being unemployed.

Conclusion: Prosthetic intervention positively influences function, independence and community participation. Challenges relating to the accessibility, cost and maintenance of prosthetics should be a priority to ensure continued functional independence for prosthetic users.
\end{abstract}

\section{Clinical relevance}

Understanding the importance of a prosthesis to a prosthetic user validates prosthetic intervention for persons living with an amputation in a rural setting and is vital in establishing and remodelling effective systems for prosthetic service delivery.

\section{Background}

The World Health Organization (WHO) estimates that more than 1 billion people are in need of one or more assistive products. ${ }^{1}$ The number of people with disabilities is increasing as a 
result of a marked increase in the incidence of chronic diseases such as diabetes and heart disease, as well as trauma, globally and also in South Africa. ${ }^{2-4}$

South Africa has a population of approximately 54 million people and is classified by the World Bank as an upper middle income country and has a national disability prevalence of 7.5\%.5 In 2013, 43.7\% of the South African population lived in rural settings. 6 Huge disparities exist in healthcare provision between public and private sectors as well as urban and rural settings 5,6

The Mpumalanga province in South Africa has a population of 4.4 million people,7 of which $61 \%$ lives in a rural setting. 6 Individuals living in rural settings generally cannot afford private medical insurance and rely on the public health sector for health services. In 2011, $84.1 \%$ of the province's population relied on the public health sector. 6 In the public health service in Mpumalanga, a person with a lower limb amputation (LLA) will be assessed by a physiotherapist at the hospital, following their amputation. If they qualify for a lower limb prosthesis, they will be referred to one of the two public prosthetic centres in the province for prosthetic fitting. 8 If the patient managed to access the prosthetic centre, they will be on a waiting list (on average 3-6 years) for prosthetic fitting (at the time of data collection) (anonymous therapist at district hospital, 2016, oral communication).

Apart from being predominantly rural, and serviced by the public health sector, the Mpumalanga province's incidence of fatalities due to road accidents is $57 \%$ higher (44 per $100,000) 9$ than that of the national average which was 25.2 per 100,000 road accidentrelated deaths in 2015.10 The province also suffers an acute shortage of orthopaedic staff and services, with only two orthopaedic surgeons working in the public sector in 2014.11 At the time of data collection in 2016, this was still the case but according to the provincial department of health's most recent annual report, this number has recently been increased to eight orthopaedic surgeons working from 5 of the 33 hospitals in the province. 12 The ratio for orthopaedic surgeons in this province is 1 to 550,000 people.

The high number of traumatic amputations in this area, can be explained by the high incidence of road traffic accidents and the shortage of orthopaedic surgeons. ${ }^{11}$ In a similar fairly rural province (Kwa-Zulu Natal) in South Africa, 2400 LLAs were being performed annually in 2016 in the public health sector. 13 Since each province's department of health is managed independently, these statistics are not available for the Mpumalanga province.

LLA is associated with significant morbidity, mortality and disability. 14,15 The loss of a limb does not only result in functional impairment but also in psychological trauma, unemployment, high insurance payments and worse quality of life (QOL). ${ }^{16-18}$ Factors that significantly influence the QOL of individuals with an amputation include employment status, the availability and use of an assistive device, use of a prosthesis, comorbidities, 
phantom limb pain and residual limb pain. ${ }^{16,17}$ Disability is a consequence of the interaction between impairments of bodily functions and contextual factors. 19 Assistive products, such as a prosthesis, can facilitate active participation in society, and an improved quality of life. 20

The Convention on the Rights of Persons with Disabilities (CRPD) and its Optional Protocol were adopted by the United Nations General Assembly in 2006 and were ratified by South Africa in 2008.21 The convention aims to ensure that persons with disabilities are able to enjoy their human rights on an equal and equitable basis. The CRPD requires all governments which ratified it, to meet the assistive technology needs of citizens. ${ }^{21}$ The WHO launched the Global Cooperation on Assistive Technology (GATE) to support countries in their efforts to comply with the CRPD. ${ }^{22}$ GATE and the CRPD strive to address the substantial gap between the need for and provision of AT. 22

The provision of assistive and prosthetic devices in the public health sector in South Africa is challenged by staff shortages, a lack of referral, training and follow-up of patients, cultural beliefs, inaccessibility of healthcare services, lack of trained rehabilitation personnel, inappropriate preparation of healthcare workers for a rural setting and the lack of resources. $23-25$

The aim of this study was to explore the experiences of current lower limb prosthetic users in relation prosthetic service delivery and the value of their prosthesis in a rural setting. This information might assist to identify gaps in prosthetic service provision in this setting.

\section{Methods}

The aim of the study was to collect in-depth data from the participants' perspectives on their experiences as a prosthetic user in a rural setting. A generic qualitative research approach 26 and an explorative design were deemed most suitable to achieve this aim. The limited sample size that could finally be recruited to participate in the study also excluded any quantitative data collection tools, as it was too small to meaningfully analyse statistically. The data were collected by means of a semi-structured interview guide, at the prosthetic department of a rural hospital in the Mpumalanga Province in South Africa. The interview guide consisted of three distinct sections, namely: (a) demographic details, cause and comorbidities, (b) rehabilitation and satisfaction with prosthetic services and (c) community experiences with the prosthesis. The first two sections consisted mostly of close-ended questions, but participants were given the opportunity to elaborate on any of the questions and add any additional comments that they felt were relevant specifically to their rehabilitation and prosthetic fitting experience. The third section consisted of openended questions, and probing questions.

For example: Initial question: 'How do you make a living/ earn income after you lost your leg?' 
Answer: 'I was given a disability grant'

Probes: Did you not work because you felt like you couldn't, or because you couldn't find work?

Participant: 'Because I couldn’t find work'.

Researcher: Why do you think you couldn't find work? Do you think your disability had something to do with it?

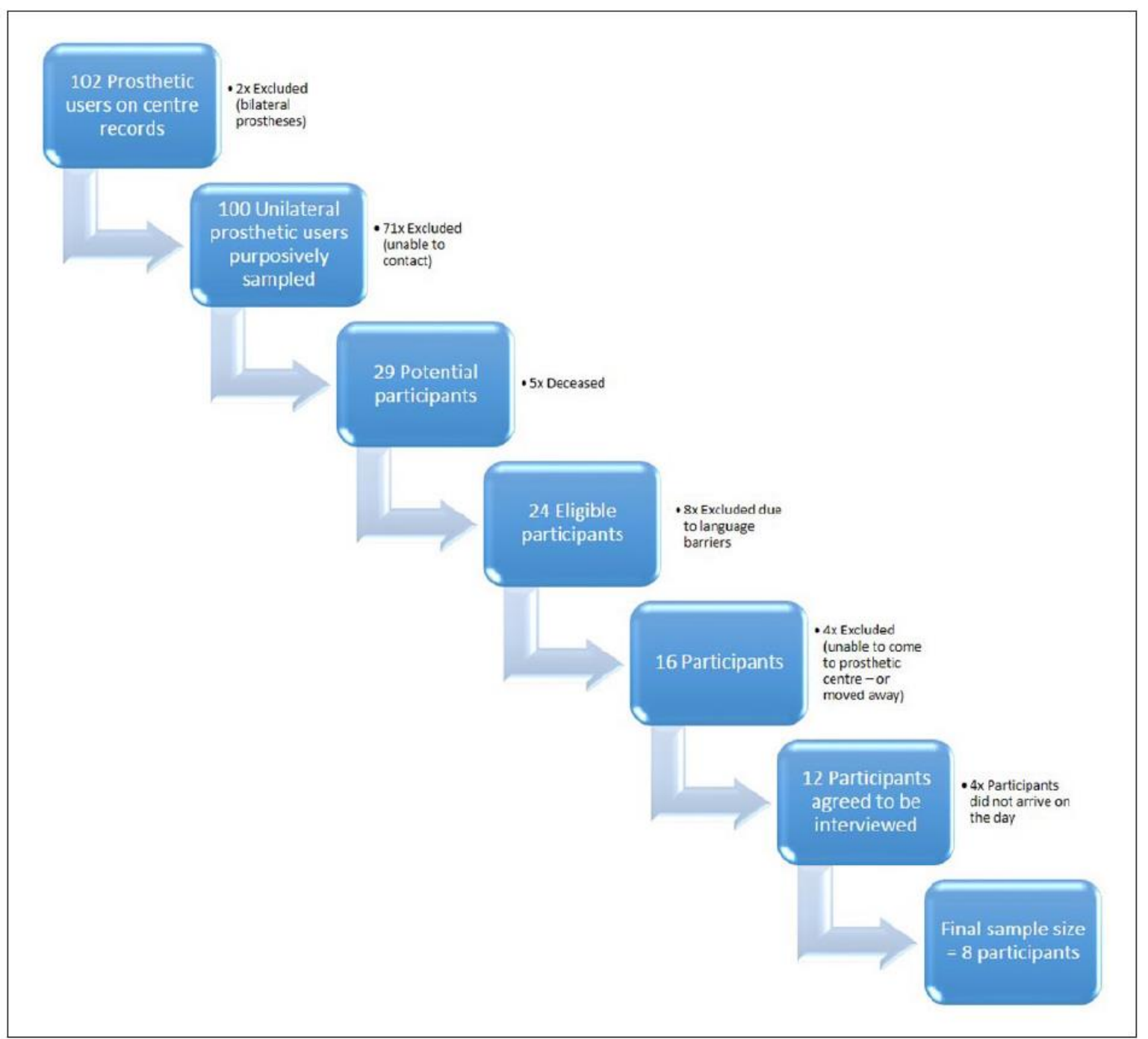

Figure I. Sampling procedure.

Participant: 'Yes and sometimes they wanted a matric certificate and I do not have one. Nowadays there are no jobs. They are only in constructions and they want people who can do a lot of physical work. Not people who can't walk'. 
Ethical clearance to conduct the study was obtained from the University of the Western Cape's Biomedical Research Ethics Committee (BM17/2/4). Permission to access the hospital and patient database was obtained from the Provincial Department of Health, the Chief Executive Officer of the Hospital, as well as the chief prosthetist at the hospital's prosthetic centre. The prosthetic centre provided the researchers with contact details of all the patients that received a lower limb prosthesis from their centre. The prosthetic centre services all persons who received a LLA in any of the 33 public hospitals in the entire province. The total population was 102 patients. The list was scrutinised and only unilateral prosthetic users were purposively included in the study sample, so two participants were excluded. The initial total sample size was thus 100 participants. All 100 prosthetic users were contacted via telephone. On the day of data collection, only eight participants arrived (Figure 1).

The response rate for this study was $37.5 \%$ of the final eligible sample of 24 . The structured interviews were conducted by a research assistant in a private room at the prosthetic department and lasted approximately $45 \mathrm{~min}$. Written informed consent was obtained from participants in any of the four most widely spoken languages namely English, Afrikaans, isiXhosa or isiZulu. The right to withdraw from the study at any time was explicitly stated. All participants were comfortable to be interviewed in English, so a translator (who was available) was not required to assist. Interviews were audio-recorded and the research assistant took field notes on the interview schedule during the interviews to ensure trustworthiness. Audio-recordings were transcribed verbatim. Demographic details and information related to the acute in-patient rehabilitation were analysed descriptively by the researcher. Qualitative data was analysed thematically. Deductive coding was used, and similar categories were grouped into themes. 27 The verbatim transcripts were read several times by the researchers in order to familiarise themselves with the content. 
Table I. Overview of themes and related categories.

\begin{tabular}{|c|c|c|}
\hline Theme & Categories & Supporting quotes \\
\hline \multirow[t]{3}{*}{$\begin{array}{l}\text { I. Challenges with access } \\
\text { to prosthetic services }\end{array}$} & I. High travel costs & $\begin{array}{l}\text { I. [PI]: 'RI } 00 \text { one way' } \\
\text { [P5]: 'It costs you R } 800 \text { private transport' }\end{array}$ \\
\hline & $\begin{array}{l}\text { 2. Challenges using public } \\
\text { transport }\end{array}$ & $\begin{array}{l}\text { 2. [P2]: 'If we get the bus then they take three or four nurses } \\
\text { who go and do their shopping. Sometimes they don't get us } \\
\text { here on time and we miss our appointment. Sometimes they } \\
\text { leave us on the street because they don't want to wait' }\end{array}$ \\
\hline & $\begin{array}{l}\text { 3. Long distances from prosthetic } \\
\text { centres }\end{array}$ & $\begin{array}{l}\text { 3. [P2]: ' } 68 \mathrm{~km} \text { one way and that is RI50' } \\
\text { [P4]: 'No it's far, maybe three hours' } \\
\text { [P5]: 'It takes me form 4:30 am till 7:45 am to get here' }\end{array}$ \\
\hline \multirow[t]{2}{*}{$\begin{array}{l}\text { 2. A lack of prosthetic } \\
\text { supplies }\end{array}$} & $\begin{array}{l}\text { I. Lack of materials for } \\
\text { manufacturing of new } \\
\text { prosthetics }\end{array}$ & $\begin{array}{l}\text { I. [P4]: 'Because the material is not able to be enough' } \\
\text { [P6]: 'l'm happy but sometimes they don't have the things' }\end{array}$ \\
\hline & $\begin{array}{l}\text { 2. Lack of materials for } \\
\text { maintenance of current } \\
\text { prosthesis }\end{array}$ & $\begin{array}{l}\text { 2. [P2]: '... because they don't always have this lining. It needs } \\
\text { the cushioning and the rim it cuts my leg a bit if I don't have } \\
\text { the lining' } \\
\text { [P8]: 'The problem is you can use this leg a long time and } \\
\text { sometimes you need new socks and they are out of socks and } \\
\text { you have to get your own socks. If you don't have socks then } \\
\text { the stump will get hurt' }\end{array}$ \\
\hline \multirow[t]{4}{*}{ 3. Participation in society } & $\begin{array}{l}\text { I. Able to ambulate independently } \\
\text { in their communities, allowing } \\
\text { participation }\end{array}$ & $\begin{array}{l}\text { I. [PI]: 'I can walk } 2-3 \text { hours' } \\
\text { [P2]: 'I can walk also for long, } 5 \text { hours' } \\
\text { [P3]: ' } 3 \mathrm{~km} \text { \{when asked how far they can walk in one stretch }\}\end{array}$ \\
\hline & $\begin{array}{l}\text { 2. Challenges accessing/ } \\
\text { completing education }\end{array}$ & $\begin{array}{l}\text { 2. [P8]: 'I had to teach myself to walk, I have to go to school ... } \\
\text { ey it was far, an hour to walk. Ey, I tried but I failed matric' } \\
\text { [P7]: 'I stopped \{school\} in grade II' } \\
\text { [P5]: 'I didn't finish school because it took a long time in } \\
\text { hospital ... finished Grade 9' }\end{array}$ \\
\hline & $\begin{array}{l}\text { 3. Lack of employment } \\
\text { opportunities }\end{array}$ & $\begin{array}{l}\text { 3. [P3]: 'I can't find work I can do' } \\
\text { [P4]: 'I want a job with my hands. Making with the wood. } \\
\text { Carpenter' } \\
\text { [P5]: 'Ay, because they told me they can't employ me' } \\
\text { [P7]: 'I wanted to work but couldn't find' }\end{array}$ \\
\hline & $\begin{array}{l}\text { 4. Active participants in their } \\
\text { communities' activities }\end{array}$ & $\begin{array}{l}\text { 4. [PI]: 'Like sports because I play basketball for the disabled. } \\
\text { Wheelchair basketball in my community in Nkomazi (my } \\
\text { community)' } \\
\text { [P2]: 'Yes, I play chess and teach kids in my area and am a } \\
\text { ward committee member' } \\
\text { [P5]: 'Yes, }\{\text { I go to }\} \text { church and school meetings ... on my own' }\end{array}$ \\
\hline
\end{tabular}

The data were then manually coded by highlighting words or phrases with a single idea that was related to the experiences of a prosthetic user in the community. Codes with similar meanings across the datasets were then grouped around a single concept (e.g. challenges with prosthetic services) into categories. Finally, categories that overlapped were then collapsed in order to form overarching themes that emerged from the data (Table 1).

\section{Results}

\section{Demographic details of participants}

In this study, the majority $(n=8)$ of the participants were male. The average age of participants at the time of data collection was 44 years (standard deviation (SD) \pm 8.9 ; range 33-64) and the majority of participants $(n=6 / 9)$ were between 40 and 49 years old. The mean age at amputation was 23 years old (range 5-56) and the mean time since amputation at data collection was 19years and 6 months ago (median 20; SD \pm 7.6 ; range 3-34). On average, according to the participants, they waited 1 year since their amputation 
for their prosthesis to be fitted (Figure 2). This could not be verified, as the hospital records for confirmation of date of amputation do not exist anymore, due to the time that has elapsed since their amputation.

\section{Causes and level of $L L A$}

The majority of participants $(n=8 / 9)$ in this study sample's amputations were caused by trauma. The most common traumatic cause $(n=4)$ was as a result of a motor vehicle accident. The other traumatic causes are illustrated in Figure 3.

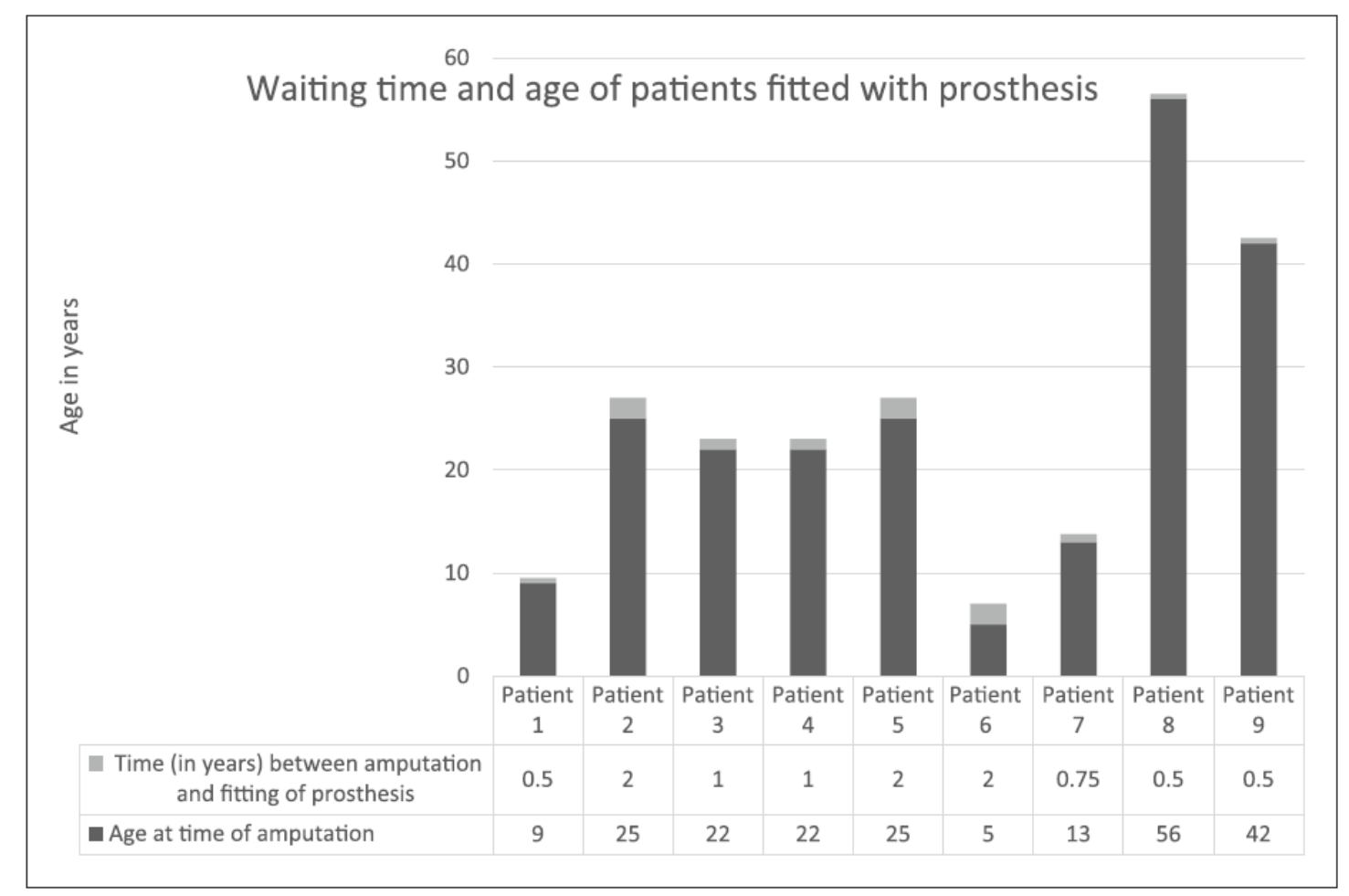

Figure 2. Age of amputation and waiting period for prosthetic fitting. 


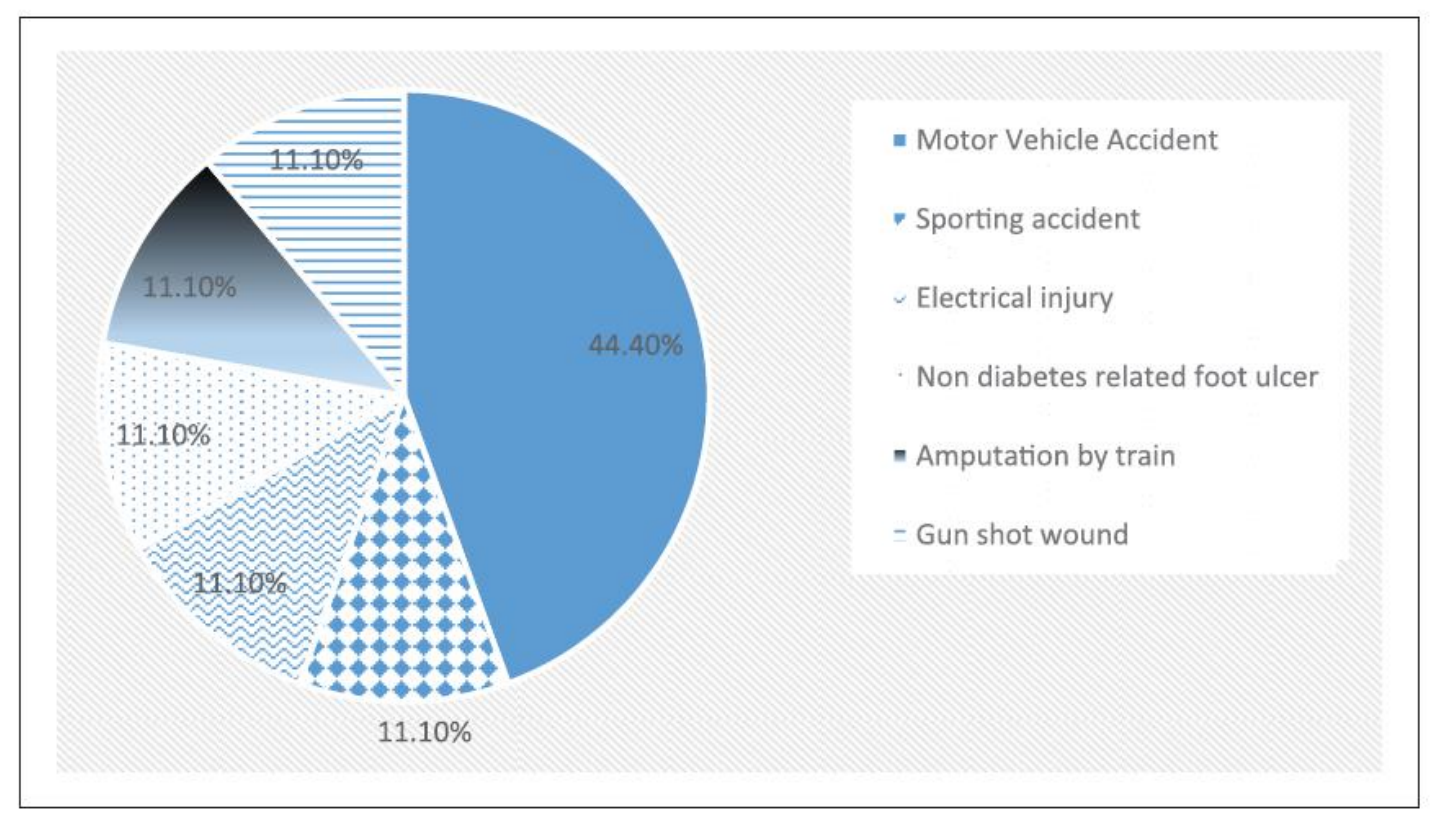

Figure 3. Causes of trauma-related lower limb amputations.

Of the total sample, two-thirds $(n=6 / 9)$ received a transfemoral amputation, while the other third suffered a trans-tibial amputation. Three out of the nine $(n=3 / 9)$ participants underwent revision surgery as a result of sepsis. No significant comorbidities were recorded.

\section{Rehabilitation}

Length of hospital stay was dependent on patient recall and cannot be considered accurate as it could not be verified by hospital records (too long since time of amputation), but ranged from 2 weeks up to 2 years. The majority $(n=7 / 9)$ of participants received postoperative physiotherapy intervention in hospital. The most common types of physiotherapy interventions received included bed-exercises and stump-bandaging (Figure 4). Only one person received pre-operative physiotherapy treatment but this patient did not receive any post-operative physiotherapy. 


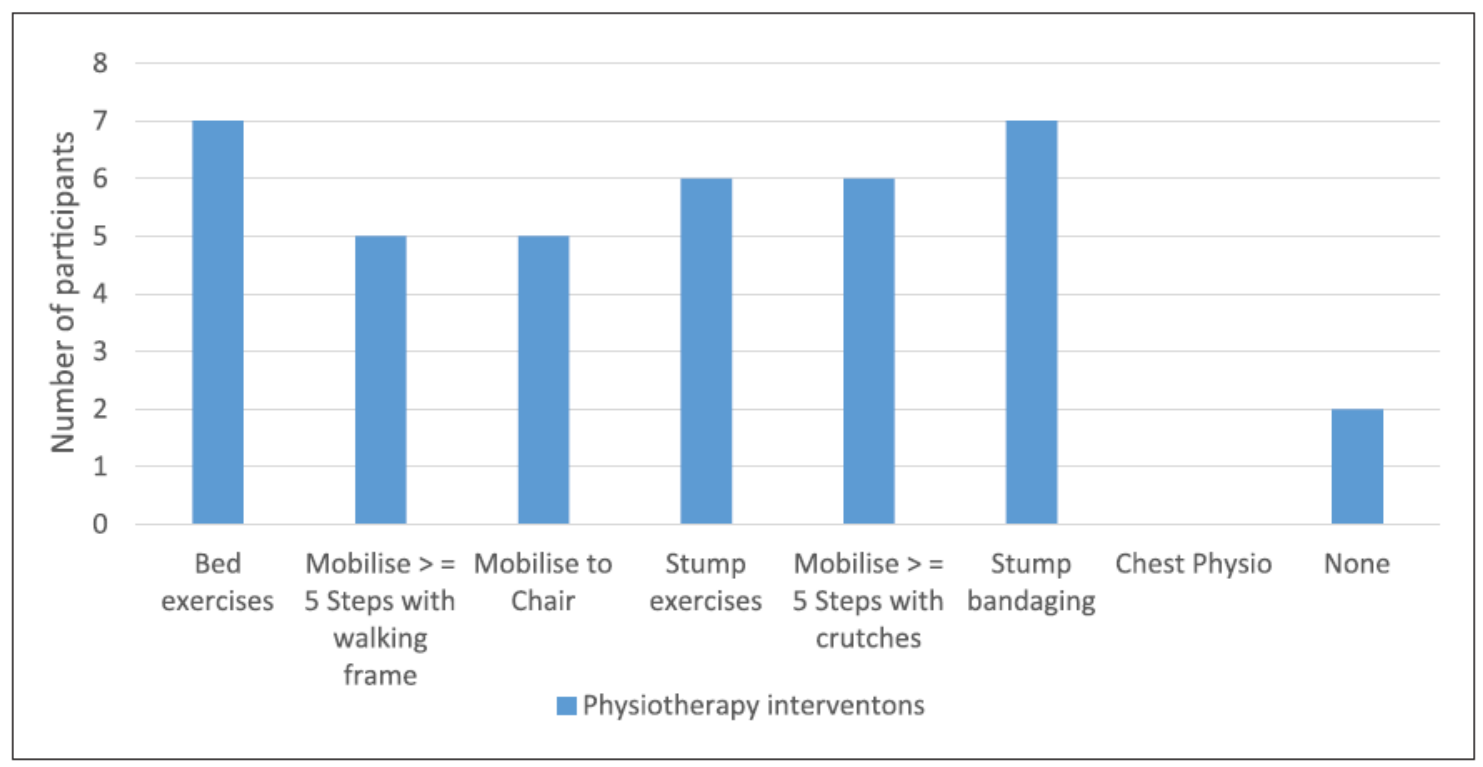

Figure 4. In-patient physiotherapy interventions.

The majority of patients $(n=7 / 9)$ were able to walk independently outdoors and climb stairs with crutches on discharge from the hospital. One participant was given a pair of crutches at discharge from hospital, but received no physiotherapy, and was not taught how to use them, and one participant was dependent on a wheelchair on discharge from acute rehabilitation after amputation. No patients were referred to subacute in-patient rehabilitation facilities for further rehabilitation after discharge from the acute hospital. All the participants were assessed by a physiotherapist to be at the $\mathrm{K}_{3}$ activity level at the time of data collection as defined by the Medicare Functional Classification Level. 28

Three themes emerged from the experiences voiced by the participants in this study. These themes included challenges with access to prosthetic services, a lack of prosthetic supplies and experiences relating to participation in society (Table 1 ).

\section{Challenges with access to prosthetic services}

All participants expressed challenges with accessing the prosthetic centre due to high travel costs, challenges with using public transport and prolonged travel time:

It costs you R80o $\{63 \mathrm{USD}\}$ private transport. [P5]

... many of us disabled people in the truck with wheelchairs and crutches. It's the truck they use to move linen etc. We have to sit on the bench and when we were driving the wheelchairs were moving and knocking into each other. [P2]

No it's far, maybe three hours. [P4] 


\section{A lack of prosthetic supplies}

A common concern among participants was that there was a lack of materials available at the hospital to manufacture a new prosthesis or maintain their current prosthesis. They made it clear that the institution is doing their best to provide a service, but that the government is not supporting it with the necessary resources:

Yes but not always, because the government doesn't provide Robs [the hospital] with the materials. [P2]

Yes I am happy, especially when there is materials. [P4]

I'm happy but sometimes they don't have the things ... socks, sponge cover. [P6]

Participants mentioned that the hospital often did not have stump socks and other materials needed for the maintenance of their prosthesis in stock. The lack of availability of stump socks negatively impacted on their function as it decreased their ability to stand or walk, by causing pain:

... they don't always have this lining. It needs the cushioning and the rim it cuts my leg a bit if I don't have the lining. [P4]

... They are out of socks and you have to get your own socks. If you don't have socks then the stump will get hurt. [P7]

\section{Participation in society}

Despite challenges with accessing prosthetic services, and a lack of available materials, all participants were very mobile with their prosthesis. Participants generally reported being able to stand for long periods of time (up to $10 \mathrm{~h}$ ), accommodate uneven terrain and inclines (although sometimes using crutches) and walk long distances. One participant even reported being able to climb trees:

When I am standing I can stand three hours to four hours. [P4] I walk for 4 hours. [P6] I can walk also for long, 5 hours. [P2] Yes, yes even [climb in] to the tree. [P3]

Participants reported occasionally needing to rest when walking long distances with their prosthesis, but the reason for this was due to fatigue:

Maybe because I am tired, no problem with the leg. [P4]

... just tired. [P6]

Being mobile in their communities enabled participants to actively participate in society:

... I am the secretary of the ward committee. I meet in disability forums and write minutes ... I go on my own. [P1] 
Yes to church ... I walk sometimes or I go with a car. [P3]

Participants were generally well integrated and active members of their society, but expressed concerns relating to unemployment. Only one participant was employed and he owned his own business. The remaining participants relied on social (disability) grants of R1600 (US\$127) per month and were unemployed. While most reported to be unemployed, participants were eager to work. Participants reported that they felt they were not employable due to their disability and because most of them did not complete school. Many expressed that they were limited in finding work in any sector other than that of manual labour. When probed, many participants felt this was because they did not complete school, usually as a direct consequence of their amputation. They were also not aware of alternative fields of suitable occupation:

I can't find work I can do. [P3]

I couldn't get a job ... like general worker or gardener. [P1]

I didn't finish school because it took a long time in hospital ... finished Grade 9. [P5]

Patients expressed that their prosthesis was a vital part of their daily lives that enabled them to be active and involved in their communities. In response to the question if they would like to be involved in making prosthetics, most participants answered very positively: Yes ... I want to work in this field ... help making these legs.

$[\mathrm{P} 1]$

I would give everything I have to make a leg. [P7]

\section{Discussion}

All the participants in this study suffered traumatic amputations. None of these participants were diagnosed with diabetes and only one of the participants was hypertensive (HPT) and one had HIV/AIDS. This finding is contrary to the current literature reporting that avascular causes such as diabetes is the most common cause of LLAs globally, even in rural settings.1,2,4 This finding can however potentially be explained by the unusually long mean time since amputation of this cohort of patients, which could bias the results. In this study, participants were all relatively young prosthetic users (mean age $=44$ years), who suffered their amputation an average of 19 years ago. Younger, healthier participants would be more likely to have been willing to attend the interviews at the hospital. Furthermore, according to the older literature, traumatic amputations used to be the most common cause of LLAs especially in rural settings and developing countries. 3 Another possible explanation given in the South African media for the high number of traumatic amputations specifically in the Mpumalanga province can be the high incidence of road traffic accidents in this province. This coupled with the low number of orthopaedic surgeons available to manage 
traumatic fractures, often results in preventable LLAs. These preventable amputations are very disconcerting, and even though the number of orthopaedic surgeons employed in the public health sector in the province has quadrupled in the last 4 years, ${ }^{12}$ measures should continue to be put in place to address the shortage of orthopaedic surgeons in the province.

Another finding that might be biased by the long time since amputation in this cohort is the average waiting period for a prosthesis in this setting. Participants in this study on average waited 1 year since amputation for their prosthesis. However, according to personal communication with rehabilitation staff at the public hospitals, persons with a LLA in rural settings at the time of data collection in 2016 waited between 3 and 6 years to be fitted with a prosthesis in the same province. The average waiting period for prosthetic fitting in a similar rural setting in the Kwa-Zulu Natal province was also 3 years. ${ }^{23}$ Even though a waiting period of 1 year for a prosthesis seems relatively short when compared to the current waiting period, it is still long enough for persons with an amputation to potentially develop the complications of immobility which could make prosthetic fitting impossible. Considering the long distances that participants had to travel and the high cost of accessing transport, it is imperative that persons with a LLA in the rural setting have access to sub-acute rehabilitation. This could be achieved either through advocating for a community-based rehabilitation approach to decentralise rehabilitation services, or providing appropriate and affordable transport to public health services.

It was clear that from the participants' perspectives, prosthetic intervention was vital to them being able to perform their daily tasks, and actively participate in their communities. Literature also supports that having access to employment and a prosthetic limb also significantly improves a person with a LLA's function, productivity and QOL.16,17 Participants in this study reported independence in all activities of daily living and were actively contributing to the maintenance of their respective households. The majority of participants received acute physiotherapy in hospital and were able to mobilise independently with crutches before discharge, but received no sub-acute in-patient rehabilitation after discharge from the hospital. Given the lack of sub-acute rehabilitation, participants were still functionally ambulant ( $\mathrm{K}_{3}$ level) within their communities and could participate actively in society. Their functional level could potentially be attributed to the young age of amputation and traumatic cause of amputation which are both associated with improved functional outcomes. 29 The functional status of patients might however be very different for a cohort of patients with different demographics, comorbidities and cause of amputation living in a different province in South Africa. Given the escalating incidence of diabetes mellitus in South Africa, complications associated with diabetes are accepted as the most common cause of amputation in South Africa, even though there are no official countrywide statistics available on this topic. A lack of pre-prosthetic rehabilitation can potentially disqualify a slightly older person with a dysvascular cause of LLA from being fitted with a prosthesis. Due to the high cost of imported prostheses, and prosthetic staff shortages, persons with an amputation are screened very strictly in order to qualify for a prosthesis in 
the public health system. If a patient developed any complications of immobility during the waiting period for a prosthesis, they would most likely not receive a prosthesis. This would negatively impact on their QOL, function and participation in society.

The lack of resources such as stump socks for maintenance of the prosthesis was the main concern in terms of prosthetic service delivery for prosthetic users in this study. These findings correspond with the findings of a study conducted in a similar rural setting in South Africa, where follow-up of patients, access to rehabilitation, a lack of government health system support and poor socioeconomic circumstances were identified as barriers to prosthetic rehabilitation. ${ }^{22}$ Despite these difficulties, the participants were generally satisfied with the provision of prosthetic services in this setting.

Participants were active and participating members of their society, but lacked employment opportunities. Participants expressed that they could not find employment because their disability jeopardised their chances to find work as manual labourers (the only opportunities that they were aware of) when compared to an able-bodied person. Participants were reliant on a disability grant due to a lack of education. All participants in this study expressed a desire to be employed as opposed to relying on the social grant as their source of income. This finding is supported by the literature which links being employed to an improved sense of self-worth, purpose and QOL.16,17 The low level of school completion and lack of employment opportunities for persons with amputations in this study accentuate the need for a skills training centre for persons with physical disabilities in this setting. Concurrently, the government, disabled peoples' organisations and private sectors should collaborate and raise awareness on appropriate employment opportunities. High-functioning prosthetic users should be prioritised to be assisted with employment in order to relieve the burden on the social grant system. Unfortunately, the unemployment rate in South Africa in 2017 was $27.7 \%$ of the total economically productive population, making any employment opportunities very scarce and competitive. 30 Training prosthetic users as prosthetists or assistants could potentially address prosthetic staff shortages as well as unemployment amongst persons with an amputation. Alternatively prosthetic users can be trained to manufacture their own prosthetics as part of a community bases approach to rehabilitation.

\section{Study limitations}

Study findings could be biased by the small sample size. The specific demographics in terms of age, language and time since amputation, also limit the generalisabilty of the findings to this cohort of patients. Due to the challenge of identifying a translator who could speak more than four languages, only participants who spoke either isiXhosa, isiZulu, English and Afrikaans (the most widely spoken languages) were included in the study. Reported length of hospital stay, and time since amputation could not be verified due to old hospital records having been destroyed. Given these limitations, and the qualitative nature of the data collected, the findings reported on in this article are not generalisable. These findings 
should only be used to provide some insight into the experiences of this specific cohort of prosthetic users in a specific rural context, or to stimulate further research on the topic.

\section{Conclusion}

Prosthetic users in this study were dependent on their prostheses for function and participation in society. Participants were generally satisfied with the provision of prosthetic services, but highlighted the challenges that they experience with accessing the services. A lack of availability of material resources for the maintenance of their prosthesis negatively affected their function. Finally, the lack of suitable employment opportunities was highlighted as a priority concern and negatively affected their QOL after losing their limb. Prosthetic and rehabilitation services in this area should focus on a community-based approach to ensure adequate pre-prosthetic rehabilitation, advocacy for improved material supplies, and focus on vocational training and opportunities.

\section{Author contribution}

All authors contributed equally in the preparation of this manuscript.

\section{Declaration of conflicting interests}

The author(s) declared no potential conflicts of interest with respect to the research, authorship, and/or publication of this article.

\section{Funding}

The author(s) disclosed receipt of the following financial support for the research, authorship, and/or publication of this article: This study was supported by the University of the Western Cape's Early Career Research Support Programme.

\section{ORCID iD}

Liezel Ennion https://orcid.org/oooo-ooo1-6108-1981 


\section{References}

1. World Health Organization (WHO). Priority assistive products list, 2017. http://www.who.int/phi/implementation/ (accessed 12 January 2018).

2. World report on disability. Washington, DC and Geneva: World Bank and World Health Organization, 2011.

3. Moxey PW, Gogalniceanu P, Hinchliffe RJ, et al. Lower extremity amputations - a review of global variability in incidence. Diabet Med 2011; 28: 1144-1153.

4. Pillay S, Lutge E and Aldous C. The burden of diabetes mellitus in KwaZulu-Natal's public sector: a 5-year perspective. South Afr Med $J$ 2016; 106(4): 384-388.

5. Statistics South Africa. Census 2011: profile of persons with disabilities in South Africa, 2014. http://www.statssa.gov. za/publications/Report-03-01-59/Report-03-01-592011.pdf (accessed 7 March 2018).

6. Rural Health Advocacy Project. Fact sheet rural health, November 2013. https://www.health-e.org.za/wp-content/ uploads/2014/o2/Updated-Rural-Fact-Sheet-27Nov-2013. pdf (accessed 15 April 2018).

7. Statistics South Africa. Mpumalanga community survey 2016 results, 2016. http://www.statssa.gov.za/?p=8150

(accessed 20 April 2018).

8. Mpumalanga Provincial Department of Health.

Mpumalanga Hospital directory. http://www.mpuhealth. gov.za/Hospitals\%2oIn\%20Mpumalanga.html (accessed 11

April 2018).

9. Health Systems Trust. South African health review 2017, 2017.

http://www.hst.org.za/publications/South\%20African\%20

Health\%20Reviews/HST\%2OSAHR\%202017\%20Web\%20 Version.pdf (accessed 22 April 2018).

10. ITF. South Africa. In: Road safety annual report 2017.

Paris: OECD Publishing. https://www.arrivealive.co.za/ documents/SA\%20Road\%2oSafety\%20Report\%202017. pdf (accessed 20 April 2018).

11. Gonzalez LL. Thousands face disability as orthopaedic services collapse, 2014. https://www.health-e.org. $\quad$ za/2014/o8/22/thousands-face-disability-orthopaedic-services-collapse/ (accessed 26 April 2018).

12. Department of Health: Mpumalanga Province (Vote no.

10), 2017. Annual report 2016/2017 financial year. http:// www.mpuhealth.gov.za/AnnualReport/Dept\%20of\%20

Health\%20Annual\%20Report\%202017.pdf (accessed 29 April 2018).

13. Naidoo O. Amputation: one of the calamities of diabetes.

Daily News. https://www.iol.co.za/dailynews/lifestyle/ amputation-one-of-the-calamitiesof-diabetes-2037988 (accessed 21 April 2018).

14. Lazzarini P, O'Rourke S, Russell A, et al. What are the key conditions associated with lower limb amputations in a major Australian teaching hospital? J Foot Ankle Res 2012; 5(1): 12. 
15. Godlwana L, Nadasan $\mathrm{T}$ and Puckree T. Global trends in incidence of lower limb amputation: a review of the literature. South Afr J Physiother 2008; 64(1): 8-12.

16. Sinha R, van den Heuvel W and Arokiasamy P. Factors affecting quality of life in lower limb amputees. Prosthet Orthot Int 2011; 35(1): 90-96.

17. Godlwana L and Stewart A. The impact of lower limb amputation on community reintegration of a population in Johannesburg: a qualitative perspective. South Afr $J$ Physiother 2013; 69(4): 48-54.

18. Zidarov D, Swaine B and Gauthier-Gagnon C. Quality of life of persons with lower-limb amputation during rehabilitation and at 3-month follow-up. Arch Phys Med Rehabil 2009; 90: $634-645$.

19. World Health Organization (WHO). Towards a common language for functioning, disability and health ICF (ICF). Geneva: World Health Organization, 2002.

20. Tebbutt E, Brodmann R, Borg J, et al. Assistive products and the Sustainable Development Goals (SDGs). Globalizat Health 2016; 12: 79.

21. UN convention on the rights of persons with disabilities. New York: United Nations, 2006.

22. World Health Organization (WHO). Global research, innovation and education in assistive technology: great summit 2017 report. Geneva: World Health Organization, 2017.

23. Ennion L and Johannesson A. A qualitative study of the challenges of providing preprosthetic rehabilitation in rural South Africa. Prosthet Orthot Int 2017; 42: 179-186.

24. Wegner L and Rhoda A. The influence of cultural beliefs on the utilisation of rehabilitation services in a rural South African context. Afr J Disabil 2015; 4(1): 128.

25. Rural Health Advocacy Project (RHAP) and Partners. The WHO global policy recommendations on increasing access to health workers in remote and rural areas through improved recruitment and retention: The South African Context (Version 2 Discussion document), 2013. http://www.rhap.org.za/wp-content/uploads/2014/o3/HumanResources-for-Rural-Health-Guidelines-WHO-SA-Context-Discussion-Document-April2013.pdf (accessed 5 November 2017).

26. Kelly M. The role of theory in qualitative health research. Fam Prac 2010; 27: 285-290.

27. Creswell JW. Qualitative enquiry and research design: choosing among five approaches, 2013. 3rd ed. London: SAGE.

28. Gailey RS, Roach KE, Applegate EB, et al. The Amputee Mobility Predictor: an instrument to assess determinants of the lower-limb amputee's ability to ambulate. Arch Phys Med Rehabil 2002; 83(5): 613-627.

29. Kahle J, Highsmith J, Schaepper H, et al. Predicting walking ability following lower limb amputation: an updated systematic review. Technol Innov 2017; 18(2-3): 125-137.

30. Menon S. SA's unemployment rate hits a 13-year high.

Sunday Times Live, 1 June 2017. https://www.timeslive. co.za/news/south-africa/2017o6-01-sas-unemployment-rate-hits-a-13-year-high/ (accessed 3 January 2018). 